\title{
Method Engineering: Trends and Challenges
}

\author{
Colette Rolland \\ CRI, Université Paris 1 Panthéon - Sorbonne, 90, rue de Tolbiac, 75013 \\ Paris, France \\ rolland@univ-paris1.fr
}

Method Engineering (ME) is the discipline to study engineering techniques for constructing, assessing, evaluating and managing methods for developing Information Systems Development Methods (ISDM). Method engineering can therefore, be seen as concerned with meta-methods. The prevalent research view point has been the one of a meta-method supporting the selection and integration of ISDM parts that together form a new situational method i.e. a method adapted to the situation of a specific ISD project. Research in Situational Method Engineering (SME) has not exclusively, but undoubtedly produced a large portfolio of assemblybased approaches.

The talk will build upon the results achieved in SME to suggest cross fertilization with other disciplines and to raise research challenges for our community.

The position of the author is on one hand, that some of the results achieved can be 'exported' to other fields to the benefit of the SME research whereas on the other hand, our discipline can expand its scope by 'importing' views and approaches that other communities are developing on similar issues.

Please use the following format when citing this chapter:

Rolland, C., 2007, in IFIP International Federation for Information Processing, Volume 244, Situational Method Engineering: Fundamentals and Experiences, eds. Ralyté, J., Brinkkemper, S., Henderson-Sellers B., (Boston Springer), pp. 6. 